\title{
Cerebral Venous Sinus Thrombosis Presenting as Ménière's Disease
}

\author{
Dong Gu Hur ${ }^{1,2}$, Kyeong Hwa Ryu ${ }^{3}$, Seong Ki Ahn ${ }^{2,4}$, and Hyun-Jin Lee ${ }^{5}$ \\ Departments of ${ }^{1}$ Otorhinolaryngology and ${ }^{3}$ Radiology, Gyeongsang National University Changwon Hospital, \\ Gyeongsang National University College of Medicine, Changwon; and \\ ${ }^{2}$ Institute of Health Sciences, Gyeongsang National University, Jinju; and \\ ${ }^{4}$ Department of Otorhinolaryngology, Gyeongsang National University Hospital, Gyeongsang National University College of Medicine, \\ Jinju; and ${ }^{5}$ Department of Otorhinolaryngology-Head and Neck Surgery, Chung-Ang University College of Medicine, Seoul, Korea
}

\section{메니에르병의 증상으로 나타난 뇌정맥동혈전증 1예}

허동구 ${ }^{1,2} \cdot$ 류경화 $^{3} \cdot$ 안성기 $^{2,4} \cdot$ 이현진 ${ }^{5}$

경상국립대학교 의과대학 창원경상국립대학교병원 ${ }^{1}$ 이비인후과학교실, ${ }^{3}$ 영상의학교실, ${ }^{2}$ 경상국립대학교 건강과학연구원,

${ }^{4}$ 경상국립대학교 의과대학 경상국립대학교병원 이비인후과학교실, ${ }^{5}$ 중앙대학교 의과대학 이비인후과학교실

\author{
Received March 31, 2021 \\ Revised May 24, 2021 \\ Accepted May 28, 2021 \\ Address for correspondence \\ Hyun-Jin Lee, MD \\ Department of Otorhinolaryngology- \\ Head and Neck Surgery, \\ Chung-Ang University \\ College of Medicine, \\ 84 Heukseok-ro, Dongjak-gu, \\ Seoul 06974, Korea \\ Tel +82-2-6299-1765 \\ Fax $+82-2-825-1765$ \\ E-mail eenigma35@gmail.com
}

We report an unusual case of cerebral venous sinus thrombosis (CVST) with dizziness similar to Ménière's disease. A 46-year-old male was initially suspected of having Ménière's disease based on his clinical manifestations. His dizziness was characterized as spinning or whirling vertigo, accompanied by aural fullness and tinnitus of the right ear. Vestibular examinations showed spontaneous nystagmus on the right, but the caloric and video head impulse tests were normal. Electrocochleography revealed a right-side abnormality. On the third day of treatment, visual symptoms and papilledema, indicating increased intracranial pressure, were observed. The central lesion was explored using MRI, and a final diagnosis of CVST was made. Anticoagulation therapy improved the patient's dizziness, aural symptoms, and papilledema. Based on our case, the diagnosis of Ménière's disease requires a more careful approach, and neurological signs and clinical manifestations should be checked to rule out central lesions such as CVST.

Korean J Otorhinolaryngol-Head Neck Surg 2021;64(10):741-5

\section{Introduction}

Cerebral venous sinus thrombosis (CVST) is a rare condition with an estimated incidence of $2-4$ per million people per year. It is characterized by the classical features of headache, dizziness, seizures, stroke, increased intracranial pressure (IICP), and various focal neurological deficits, with frequent deterioration of consciousness to progressive coma and death. ${ }^{1)}$ However, the symptoms of CVST, including dizziness,

This is an Open Access article distributed under the terms of the Creative Commons Attribution Non-Commercial License (https://creativecommons.org/licenses/by-nc/4.0) which permits unrestricted non-commercial use, distribution, and reproduction in any medium, provided the original work is properly cited. may be non-specific and subtle. Ménière's disease is an inner ear disorder characterized by a symptom complex of episodic vertigo, fluctuating hearing loss, tinnitus, and aural fullness. ${ }^{2)}$ The dizziness is characterized mainly by a whirling sensation in the acute phase, and the disease typically presents with unilateral aural symptoms that can persist for several decades. Diagnosis of Ménière's disease is based on clinical data and accompanying aural symptoms. ${ }^{4)}$ However, as there is no objective diagnostic test and the natural course of Ménière's disease varies markedly among cases, differentiation from other causes of dizziness, including a number of central pathologies, is essential. Here, we report a rare case of CVST in a patient 
with dizziness presenting as Ménière's disease, along with a discussion of the possible underlying mechanisms.

\section{Case}

A 46-year-old male presented to our outpatient clinic with dizziness that had started 3 weeks earlier. His medical, surgical, and family histories were unremarkable. The dizziness was characterized as a whirling sensation that lasted for several hours regardless of posture, and lightheadedness that continued even after the acute symptoms had resolved. He had experienced four episodes of vertigo during the 3 weeks since onset, none of which had lasted for more than 12 hours. The dizziness was accompanied by aural fullness and tinnitus of the right ear, followed by nausea and vomiting. At the time of the visit, his aural fullness had partially improved, and the results of pure-tone audiometry at low frequencies were normal. Vestibular assessment by videonystagmography revealed spontaneous nystagmus on the right side in all positions, but the bithermal caloric test showed normal caloric responses. Downbeat nystagmus was evident in the spontaneous nystagmus test and right-sided Dix-Hallpike test, but not in the roll test or left-sided Dix-Hallpike test. The vestibular evoked myogenic potential was normal, and there was no catch-up saccade in the video head impulse test (vHIT). The ratio of the summating potential (SP) to action potential (AP) measured by electrocochleography $(\mathrm{ECoG})$ was abnormal on the right $(0.375)$ and normal on the left (0.212) (Fig. 1). Based on these findings, we diagnosed the patient with probable acute-stage Ménière's disease associated with irritative nystagmus. He was hospitalized for medical management of his symptoms, and initially treated with thiazide diuretics, betahistine, and a vestibular suppressant. On the third hospital day, he complained of blurred vision and a feeling of increased intraocular pressure. After additional detailed history-taking, we found that his visual symptoms accompanied the onset of dizziness and had worsened after hospitalization. The remainder of the neurological examination was normal. An ophthalmic consultation detected bilateral optic disc edema, confirming the papilledema with suspected IICP. Contrast-enhanced MRI of the brain was performed to exclude central lesions and showed multiple tubular and linear filling defects in the distal superior sagittal sinus, both transverse sinuses, sigmoid sinuses, and internal jugular veins (Fig. 2). Additional serological and routine blood markers were normal, including the peripheral white blood cell (WBC) count, the erythrocyte sedimentation rate (ESR), the levels of C-reactive protein (CRP), anti-phospholipid and anti-cardiolipin antibodies, and proteins $\mathrm{C}$ and $\mathrm{S}$, the Leiden factor $\mathrm{V}$ mutation and a prothrombin mutation, and the levels of antithrombin III, factor VIII, and D-dimer. After neurological consultation, anticoagulation therapy was considered because CVST was thought to be the cause of the IICP. As there were no parenchymal lesions or other symptoms, the novel oral anticoagulant rivaroxaban (20 mg once daily) was started. Antibiotics were not prescribed because there was no evidence of acute infection. After treatment, the nystagmus improved within a few days, as did the dizziness and aural fullness. Initial medications were stopped early after confirming that symptoms had resolved, and anticoagulant treatment was continued. An ophthalmic examination performed after 3 weeks of treatment showed improvement of the papilledema. Currently, anticoagulation therapy has been maintained for more than 3 months, and there has been no symptom recurrence on follow-up.

\section{Discussion}

In our patient, the characteristics, frequency, and duration of the dizziness, accompanying aural symptoms, and positive ECoG results met the diagnostic criteria for probable Ménière's disease. ${ }^{4)}$ On the other hand, spontaneous nystagmus without canal paresis, downbeat nystagmus triggered by several positioning tests, no catch-up saccade in the vHIT, visual disturbance, and a feeling of increased intraocular pressure as comorbid symptoms were suggestive of a central lesion.

However, the spontaneous nystagmus was in the direction of the affected ear, as is that of the irritative nystagmus associated with Ménière's disease. Also, downbeat nystagmus can be observed in patients with Ménière's disease, attributable to either an asymmetrical, vertical vestibulo-ocular reflex or saccular dysfunction. ${ }^{5)}$ In addition, approximately $30 \%$ of Ménière's disease patients have normal vestibular function, i.e., a normal caloric response, ${ }^{6}$ and the discrepancies between evaluation of the lateral semicircular canal function using the vHIT and canal paresis in the caloric test are well known, especially in Ménière's disease. The hypothesized mechanism of canal paresis in Ménière's disease is not a true decrease in vestibular function, but rather enlargement of the inner diameter of the lateral semicircular canal by endolymphatic hydrops, lowering the response to temperature stimuli. ${ }^{7)}$ For these reasons, the patient was first diagnosed with Ménière's disease; the CVST was not identified until MRI was performed because of 

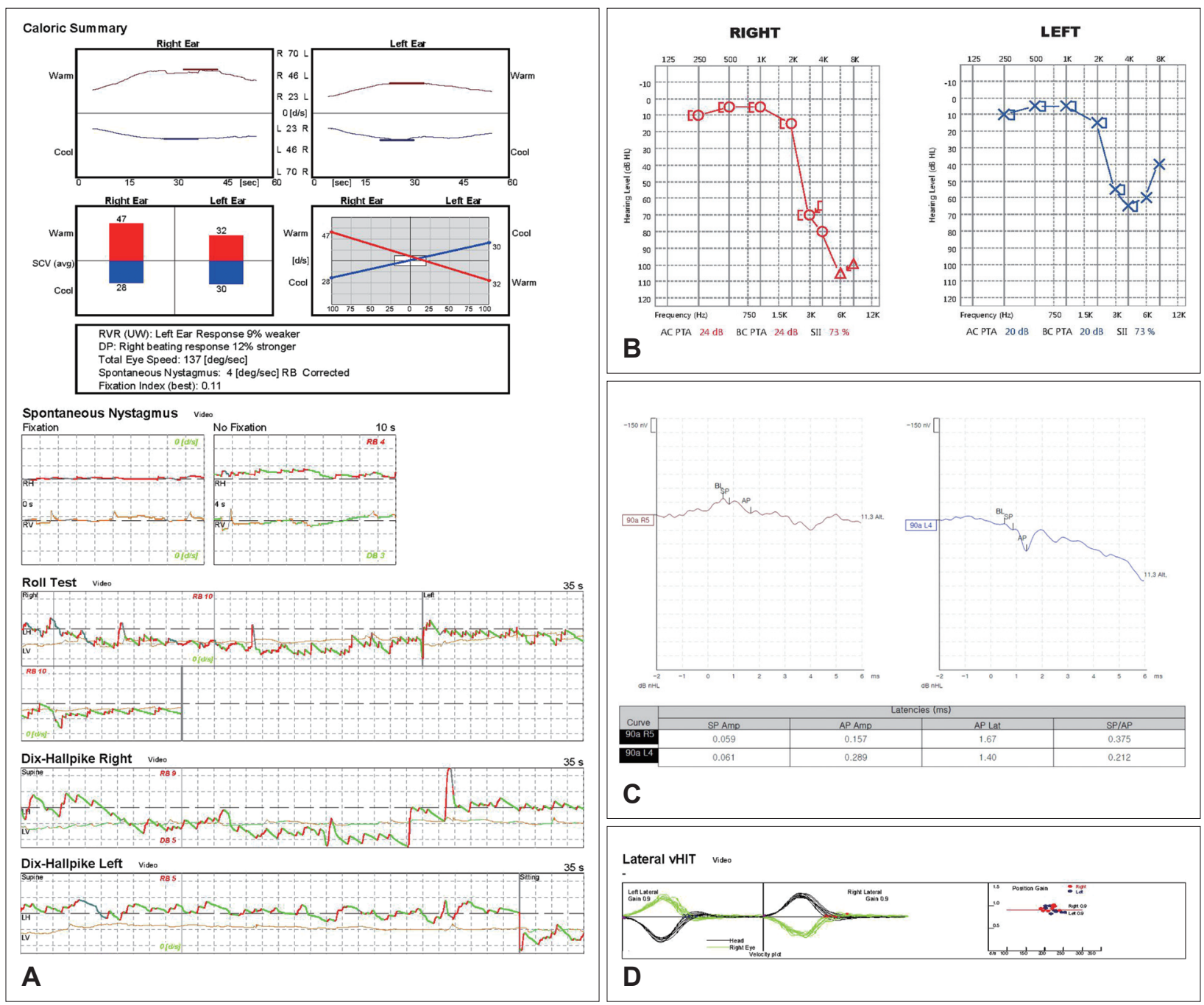

Fig. 1. The results of vestibular function tests in our patient. A: Videonystagmography showed spontaneous nystagmus to the right in all positioning tests with a normal caloric response. Downbeat nystagmus was observed in the spontaneous nystagmus test and right-sided Dix-Hallpike test, but not in the roll test or left-sided Dix-Hallpike test. B: Pure-tone audiometry showed bilateral high-frequency hearing loss but normal low-frequency hearing. C: The ratio of the summating to action potentials on electrocochleography was increased in the right ear and normal in the left ear. D: In the video head impulse test, the gain was within the normal range, and no catch-up saccade was observed.

the visual symptoms. Therefore, in the diagnosis of Ménière's disease, comprehensive assessment including thorough medical and surgical history-taking and a battery of vestibular tests is recommended, and the possibility of other causes of dizziness including central lesions, should always be considered.

Female sex, pregnancy, contraceptive pill use, coagulopathies, a malignancy, and intracranial/head-and-neck infections such as otitis and sinusitis have all been associated with CVST. However, the precise etiology remains unknown in approximately one-third of cases. ${ }^{8)}$ In our case, the patient was male, did not take any medication, had no fever, and the serological and routine blood markers including the WBC count, the ESR, and the CRP level were normal. In addition, neither endosco- py nor MRI revealed an adjacent acute infection. Therefore, the cause of CVST could not be identified. The first-line imaging technique for evaluation of patients with possible CVST is $\mathrm{CT}$ because this is available in emergency departments and can reveal local complications associated with the CVST. Currently, MRI, and MR angiography and venography, are the standard imaging techniques for diagnosis of CVST.9) Treatment features, principally, antithrombotic therapy, management of the IICP, and efficient seizure control. Thrombolysis should be used only in carefully selected patients because of the risk of bleeding. CVST was considered life-threatening in the past, but the outcomes have improved over the years, and the mortality rate has decreased from over $50 \%$ to $5 \%-10 \%{ }^{10)}$ 

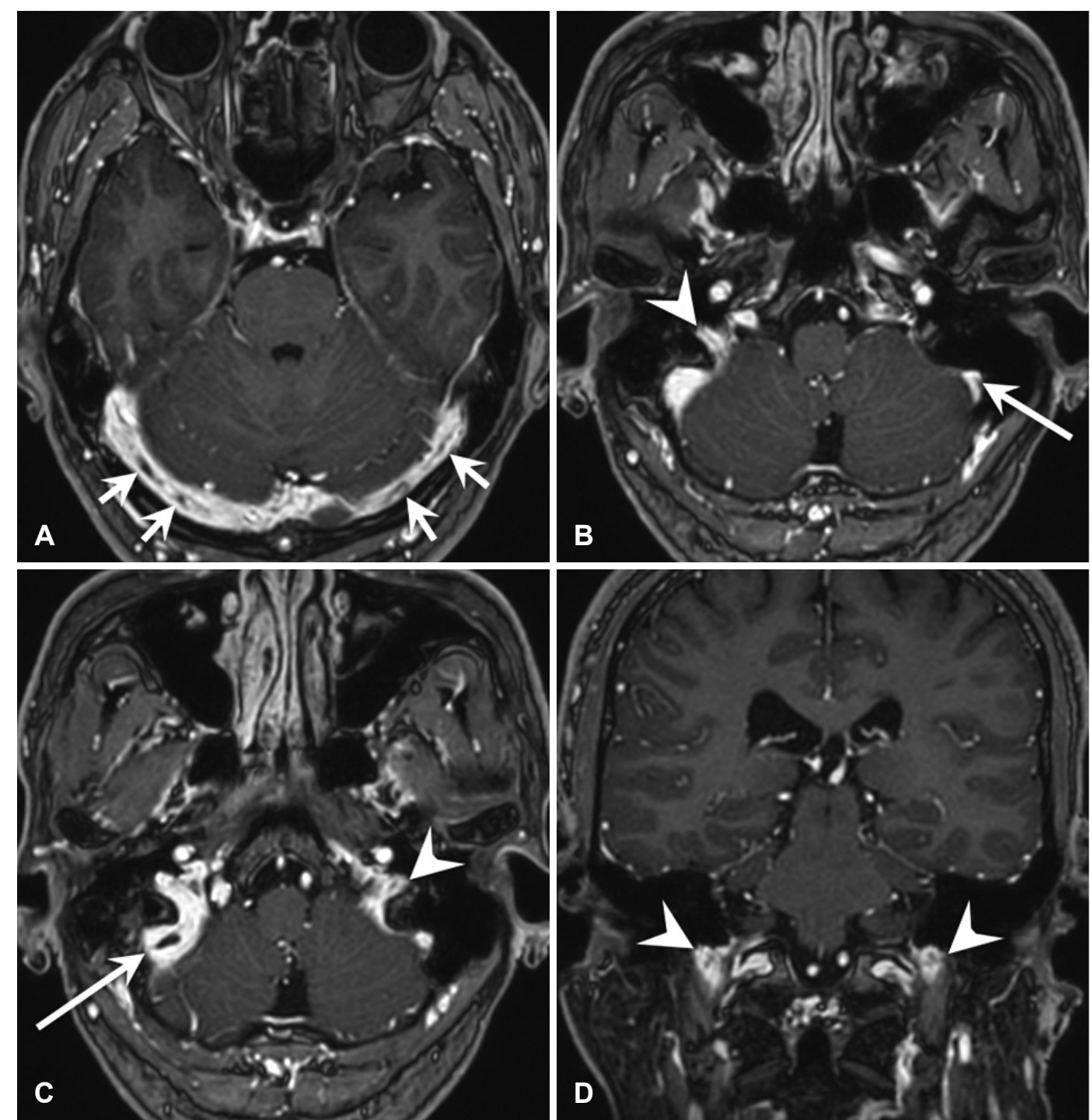

Fig. 2. Gadolinium-enhanced T1-weighted MRI of the brain. The axial (A-C) and coronal (D) images show multiple partial filling defects suggesting dural venous sinus thrombosis in both transverse sinuses (short arrows), sigmoid sinuses (long arrows), and internal jugular veins (arrowheads). The right dural venous sinuses are the dominant venous drainage in this patient.

Our patient lacked the headache and fever that are typical symptoms of CVST. On MRI, the thrombosis exhibited partial filling defects without venous infarcts. In addition, the onset of ophthalmic symptoms was delayed until several days after the onset of vertigo. Thus, we suggest that there were no related symptoms typical of CVST because it did not completely block venous flow. Aural fullness and tinnitus were evident only in the right ear, and the SP/AP ratio of the right ear was increased to 0.375 , whereas that of the left ear was normal. On MRI, the transverse sinus, sigmoid sinus, and internal jugular vein showed similar degrees of thrombus on both sides, so it would be difficult to explain the difference between the two sides based on the extent of the thrombus. However, as the right venous drainage system was dominant in this pa- tient, the possibility of more severe right-sided venous congestion despite a similar degree of thrombus might have resulted in the right-sided symptoms.

There are two possible mechanisms for dizziness in CVST. The first is disturbance of the microvascular circulation. The anterior and posterior vestibular veins carry blood from the saccule, utricle, and ampulla of the semicircular canal and meet the common modiolar vein from the cochlea to form a vein of the cochlear aqueduct, which is connected to the inferior petrosal sinus and drains into the internal jugular vein. The veins of the semicircular canal form a vein of the vestibular aqueduct and drain into the sigmoid sinus. Therefore, thrombosis of the sigmoid sinus or internal jugular vein can produce venous overload and congestion of the inner ear 
structures, which can reduce vestibular organ function, as in our patient. Based on the same mechanism, Kim, et al. ${ }^{11)}$ reported a case of dizziness presenting as acute unilateral vestibulopathy in CVST, and Honma, et al. ${ }^{12)}$ reported a case of severe dizziness induced by idiopathic internal jugular vein thrombosis. Second, IICP induced by CVST may affect the pressure of the inner ear endolymph. Several reports have shown that IICP can impair the cochlear and vestibular systems. ${ }^{13,14)}$ The proposed mechanism is that IICP is transmitted to the cochlear aqueduct and internal auditory canal, compressing the vestibulocochlear nerve or endolymphatic system, causing increased tension. Moreover, direct compression or decreased vascular supply of the endolymphatic sac causes malabsorption of endolymphatic fluid, resulting in symptoms due to endolymphatic fluid overload. ${ }^{15)}$ The elevated SP/AP ratio on ECoG in our patient can be explained by this hypothesis. SP reflects depolarization of hair cells in the organ of Corti and increases when the basilar membrane is translocated toward the scala tympani by an increase in endolymphatic pressure. Therefore, when the endolymphatic fluid is overloaded or tension is increased by IICP, the SP/AP ratio may be elevated, as in Ménière's disease. As the pathogenesis of Ménière's disease is closely related to high endolymphatic fluid pressure, it is thought that these mechanisms resulted in the dizziness in our patient appearing similar to that of Ménière's disease. Thus, although not performed in this study, follow-up ECoG would be worth considering after IICP has normalized.

In conclusion, this report describes a rare case of CVST presenting as Ménière's disease. Our patient had sufficient findings on otological evaluation to suggest a diagnosis of probable Ménière's disease, but the final diagnosis was CVST causing IICP. Therefore, clinicians should be careful when diagnosing Ménière's disease based only on clinical manifestations, and the accompanying neurological signs should be evaluated carefully.

\section{Acknowledgments}

None.

\section{Author Contribution}

Conceptualization: Kyeong Hwa Ryu, Seong Ki Ahn, Hyun-Jin Lee. Data curation: Dong Gu Hur, Kyeong Hwa Ryu. Formal analy- sis: Dong Gu Hur, Hyun-Jin Lee. Investigation: Kyeong Hwa Ryu. Project administration: Seong Ki Ahn. Resources: Seong Ki Ahn. Supervision: Hyun-Jin Lee. Visualization: Kyeong Hwa Ryu. Writing — original draft: Dong Gu Hur, Hyun-Jin Lee. Writing - review \& editing: Hyun-Jin Lee.

\section{ORCID}

Hyun-Jin Lee https://orcid.org/0000-0001-7472-830X

\section{REFERENCES}

1) Coutinho J, de Bruijn SF, Deveber G, Stam J. Anticoagulation for cerebral venous sinus thrombosis. Cochrane Database Syst Rev 2011;2011(8):CD002005.

2) Gates GA. Ménière's disease review 2005. J Am Acad Audiol 2006;17(1):16-26.

3) Basura GJ, Adams ME, Monfared A, Schwartz SR, Antonelli PJ, Burkard R, et al. Clinical practice guideline: Ménière's disease. Otolaryngol Head Neck Surg 2020;162(2_suppl):S1-55.

4) Lopez-Escamez JA, Carey J, Chung WH, Goebel JA, Magnusson M, Mandalà M, et al. Diagnostic criteria for Menière's disease. J Vestib Res 2015;25(1):1-7.

5) Lee SU, Kim HJ, Choi JY, Kim JS. Ictal downbeat nystagmus in Ménière disease: A cross-sectional study. Neurology 2020;95(17): e2409-17.

6) Neff BA, Staab JP, Eggers SD, Carlson ML, Schmitt WR, Van Abel KM, et al. Auditory and vestibular symptoms and chronic subjective dizziness in patients with Ménière's disease, vestibular migraine, and Ménière's disease with concomitant vestibular migraine. Otol Neurotol 2012;33(7):1235-44.

7) McGarvie LA, Curthoys IS, MacDougall HG, Halmagyi GM. What does the dissociation between the results of video head impulse versus caloric testing reveal about the vestibular dysfunction in Ménière's disease? Acta Otolaryngol 2015;135(9):859-65.

8) Ameri A, Bousser MG. Cerebral venous thrombosis. Neurol Clin 1992;10(1):87-111.

9) Capecchi M, Abbattista M, Martinelli I. Cerebral venous sinus thrombosis. J Thromb Haemost 2018;16(10):1918-31.

10) Coutinho JM, Zuurbier SM, Stam J. Declining mortality in cerebral venous thrombosis: A systematic review. Stroke 2014; 45(5):1338-41.

11) Kim HA, Sohn SI, Lee H. Cerebral venous thrombosis mimicking acute unilateral vestibulopathy. Neurol Sci 2008;29(1):41-3.

12) Honma H, Ohno T, Matsuzaki T, Mizuno K. Idiopathic internal jugular vein thrombosis in a patient with severe dizziness. J Echocardiogr 2011;9(3):119-20.

13) Çoban K, Aydın E, Özlüoğlu LN. Audio-vestibular findings in increased intracranial hypertension syndrome. J Int Adv Otol 2017;13(1):100-4.

14) Fontaine N, Charpiot A, Debry C, Gentine A. A case of spontaneous intracranial hypotension: From Ménière-like syndrome to cerebral involvement. Eur Ann Otorhinolaryngol Head Neck Dis 2012; 129(3):153-6.

15) Tandon PN, Sinha A, Kacker SK, Saxena RK, Singh K. Auditory function in raised intracranial pressure. J Neurol Sci 1973;18(4): 455-67. 